\title{
optimasi Pendistribusian Raskin dengan Menggunakan Goal Programming
}

\author{
Leliana Radena ${ }^{*}$, Yohanes A.R.Langia, Tohap Manurunga \\ aJurusan Matematika, FMIPA, Unsrat, Manado
}

\section{KA T A KUNCI}

Goal Programming

KEYW OR D S

Goal Programming

\begin{tabular}{l} 
A B S T R A K \\
Tujuan dari penelitian ini adalah untuk mengetahui berapa jumlah \\
raskin yang didistribusi untuk tiap bulan agar seluruh RTS yang ada \\
mendapatkan jumlah raskin yang sama. Data yang dibutuhkan dalam \\
mengoptimalkan pendistribusian raskin adalah banyaknya raskin yang \\
didistribusi pada tahun 2004-2011, waktu pendistribusian raskin di \\
empat daerah dan jumlah Rumah Tangga Sasaran (RTS) penerima raskin. \\
Hasilnya menunjukan jumlah raskin yang didistribusikan setiap bulan \\
untuk empat daerah pada periode $2004-2011$ yaitu untuk daerah \\
Manado pada tahun 2004 yaitu $7.1 \mathrm{~kg}$, daerah Gorontalo pada tahun \\
2005 yaitu $12 \mathrm{~kg}$, pada tahun daerah Tahuna pada tahun 2006 yaitu 12 \\
kg, dan daerah Bolaang Mongondow pada tahun 2007 yaitu $10 \mathrm{~kg}$. \\
A B S T R A C T \\
The purpose of this research was to determine how many Raskin \\
were distributed for each month that all target households that is getting \\
the same amount of rice for. The data needed to optimize the distribution \\
of Raskin is the number that is distributed in the year $2004-2011$, Raskin \\
time distribution in the four regions and the number of Target Households, \\
receiver Raskin. The results show that distributed Raskin amount each \\
month for the four regions in the period $2004-2011$ is to Manado area in \\
2004 is $7.1 \mathrm{~kg}$, Gorontalo area in 2005 is 12 kg, in Tahuna area in \\
2006, which is $12 \mathrm{~kg}$, and the Bolaang Mongondow in 2007 which is $10 \mathrm{~kg}$. \\
\hline
\end{tabular}

AVAILABLE ONLINE

29 Januari 2013

\section{Pendahuluan}

Permasalahan mendasar yang dihadapi selama program raskin dilaksanakan di empat daerah Manado, Gorontalo, Tahuna dan Bolaang Mongondow sejak tahun 2004 - 2011 belum dapat dijangkaunya semua rumah tangga sasaran (RTS) yang ada di empat daerah tersebut. Untuk mengantisipasi penyimpangan tersebut maka diperlukan suatu metode yakni untuk mengetahui berapa jumlah raskin yang didistribusikan untuk setiap bulan per kepala keluarga agar seluruh RTS mendapatkan raskin. Salah satu model yang tersedia dalam matematika yang digunakan dalam penelitian-penelitian terdahulu sebagai solusi pemecahan masalah dalam pengambilan masalah multi sasaran adalah model goal programming.

\section{Metode}

Data yang digunakan dalam penelitian ini adalah data primer yang diambil dari Perum Bulog Manado yaitu berupa data :

1. Banyaknya raskin yang didistribusi pada tahun 2004-2011

2. Waktu pendistribusian raskin di empat daerah yaitu daerah Manado, Gorontalo, Tahuna dan Bolaang Mongondow.

3. Jumlah Rumah Tangga Sasaran (RTS) penerima Raskin

Adapun gambaran dari metode penelitian yang akan penulis gunakan dalam proses penyelesaian masalah perencanaan pendistribusian raskin diperlukan beberapa tahap penyelesaian, yaitu :

1. Mendefinisikan masalah pendistribusian

*Corresponding author: Jurusan Matematika FMIPA UNSRAT, Jl. Kampus Unsrat, Manado, Indonesia 95115; Email address: leliana_raden@yahoo.com Published by FMIPA UNSRAT (2013) 
2. Menentukan metode pemecahan yang akan diambil dalam memecahkan masalah pendistribusian

3. Pengumpulan dan pengolahan data yang diperlukan dalam menyelesaikan masalah pendistribusian

4. Pembentukan model matematika dari data yang diperoleh. Dalam hal ini model yang digunakan adalah model pemograman linier dengan metode Goal Programming dengan masalah yang dipilih :

a. Penetapan tujuan atau target

b. Penentuan variabel-variabel yang digunakan

c. Penentuan fungsi kendala model

5. Menyelesaikan model matematika tersebut dengan metode simplex. Tetapi karena terlalu rumit menyelesaikannya dengan manual, maka dalam hal ini digunakan perangkat lunak computer yaitu Lindo.

Mengenalisa hasil yang optimal dari penyelesaian masalah dengan program Lindo.

\section{Hasil dan Pembahasan}

Data yang dibutuhkan dalam mengoptimalkan pendistribusian ditunjukkan dalam Tabel 1, Tabel 2, dan Tabel 3.

Tabel 1 - Jumlah raskin yang telah didistribusikan untuk empat daerah pada tahun 2004-2011.

\begin{tabular}{|l|l|l|l|l|}
\hline & $\begin{array}{c}\text { Manado } \\
(\mathrm{Kg})\end{array}$ & $\begin{array}{c}\text { Gorontalo } \\
(\mathrm{Kg})\end{array}$ & $\begin{array}{c}\text { Tahuna } \\
(\mathrm{Kg})\end{array}$ & $\begin{array}{c}\text { Bol-Mong } \\
(\mathrm{Kg})\end{array}$ \\
\hline 2004 & 9.843 .562 & 11.186 .000 & 3.261 .370 & 4.176 .067 \\
\hline 2005 & 11.010 .960 & 9.728 .000 & 3.401 .080 & 4.306 .320 \\
\hline 2006 & 6.287 .520 & 7.375 .000 & 2.514 .760 & 3.177 .240 \\
\hline 2007 & 7.104 .213 & 11.429 .498 & 2.686 .334 & 3.530 .953 \\
\hline 2008 & 11.444 .650 & 17.977 .050 & 4.827 .900 & 6.003 .025 \\
\hline 2009 & 12.294 .900 & 14.641 .920 & 5.186 .520 & 6.448 .680 \\
\hline 2010 & 10.624 .926 & 13.045 .645 & 4.625 .238 & 5.770 .520 \\
\hline 2011 & 11.910 .960 & 12.647 .041 & 4.517 .460 & 4.414 .680 \\
\hline Total & 80.521691 & 98.030154 & 30.120662 & 37.827485 \\
\hline
\end{tabular}

Tabel 2 - Tabel waktu pendistribusian raskin

\begin{tabular}{|l|c|c|c|c|}
\hline & Manado & Gorontalo & Tahuna & Bol_Mong \\
\hline 2004 & 12 & 12 & 12 & 12 \\
\hline 2005 & 12 & 10 & 10 & 13 \\
\hline 2006 & 10 & 12 & 12 & 10 \\
\hline 2007 & 12 & 13 & 10 & 12 \\
\hline 2008 & 13 & 10 & 12 & 10 \\
\hline 2009 & 10 & 10 & 12 & 13 \\
\hline 2010 & 12 & 12 & 13 & 10 \\
\hline 2011 & 13 & 13 & 12 & 10 \\
\hline
\end{tabular}

Tabel 3 - Jumlah RTS setiap KK untuk empat daerah

\begin{tabular}{|r|r|r|r|r|}
\hline Tahun & Manado & Gorontalo & Tahuna & BolMong \\
\hline 2004 & 94.704 & 111.860 & 27.642 & 24.612 \\
\hline 2005 & 102.687 & 81.066 & 28.339 & 24.957 \\
\hline 2006 & 52.396 & 61.458 & 20.956 & 26.477 \\
\hline 2007 & 59.201 & 114.294 & 22.386 & 29.424 \\
\hline 2008 & 72.741 & 149.808 & 27.588 & 26.960 \\
\hline 2009 & 65.880 & 122.016 & 24.986 & 24.417 \\
\hline 2010 & 59.506 & 70.517 & 25.097 & 31.192 \\
\hline 2011 & 66.172 & 105.392 & 25.097 & 24.526 \\
\hline
\end{tabular}

\subsection{Pengolahan Data}

Data yang telah diolah pada masalah pendistribusian raskin ditunjukkan dalam Tabel 4 dan Tabel 5.

Tabel 4 - Data hasil penghitungan jumlah raskin berdasarkan waktu pendistribusian di empat daerah

\begin{tabular}{|l|l|l|l|l|}
\hline & Manado & Gorontalo & Tahuna & $\begin{array}{c}\text { Bol- } \\
\text { Mong }\end{array}$ \\
\hline 2004 & 820296 & 932166 & 271780 & 348005 \\
\hline 2005 & 917580 & 972800 & 340108 & 331255 \\
\hline 2006 & 628752 & 614583 & 209563 & 317724 \\
\hline 2007 & 592017 & 879192 & 268633 & 294246 \\
\hline 2008 & 880357 & 1797705 & 402325 & 600302 \\
\hline 2009 & 1229490 & 1464192 & 432210 & 496052 \\
\hline 2010 & 885410 & 1087137 & 355787 & 577052 \\
\hline 2011 & 916227 & 972849 & 376455 & 441468 \\
\hline
\end{tabular}

Tabel 5 - Tabel jumlah RTS setiap KK berdasarkan waktu pendistribusian untuk empat daerah periode $2004-2011$

\begin{tabular}{|l|l|l|l|l|}
\hline \multicolumn{1}{|l|}{} & Manado & Gorontalo & Tahuna & $\begin{array}{l}\text { Bol- } \\
\text { Mong }\end{array}$ \\
\hline 2004 & 1136448 & 1342320 & 331704 & 295344 \\
\hline 2005 & 1232244 & 810660 & 283390 & 324441 \\
\hline 2006 & 523960 & 737496 & 251472 & 264770 \\
\hline 2007 & 710412 & 1485822 & 223860 & 353088 \\
\hline 2008 & 945633 & 1498080 & 331056 & 269600 \\
\hline 2009 & 658800 & 1220160 & 299832 & 317421 \\
\hline 2010 & 714072 & 846204 & 326261 & 311920 \\
\hline 2011 & 860236 & 1370096 & 301164 & 245260 \\
\hline
\end{tabular}

\subsection{Pemecahan Masalah}

Data yang diolah akan digunakan untuk pemecahan masalah pendistribusian raskin dengan menerapkan disiplin ilmu operation Research khususnya goal programming.

Langkah-langkah penyelesaian masalah dapat diuraikan sebagai berikut : 


\subsubsection{Pengembangan Model}

1. Penetapan tujuan atau target

2. Penetuan Variabel-variabel

$X_{A 1}, X_{A 2}, X_{A 3}, X_{A 4}, X_{A 5}, X_{A 6}, X_{A 7}, X_{A 8}=$ Jumlah Raskin yang didistribusikan tiap bulan untuk daerah manado pada tahun 2004 - 2011

$X_{B 1}, X_{B 2}, X_{B 3}, X_{B 4}, X_{B 5}, X_{B 6}, X_{B 7}, X_{B 8}=$ Jumlah Raskin yang didistribusikan tiap bulan untuk daerah Gorontalo pada tahun 2004 - 2011

$X_{C 1}, X_{C 2}, X_{C 3}, X_{C 4}, X_{C 5}, X_{C 6}, X_{C 7}, X_{C 8}=\quad$ Jumlah Raskin yang didistribusikan tiap bulan untuk daerah Tahuna pada tahun 2004 - 2011

$X_{D 1}, X_{D 2}, X_{D 3}, X_{D 4}, X_{D 5}, X_{D 6}, X_{D 7}, X_{D 8}=$ Jumlah Raskin yang didistribusikan tiap bulan untuk daerah Bolaang Mongondow pada tahun 2004 2011

$a_{i j}=$ Jumlah RTS per bulan

$b_{i}=$ Jumlah Raskin yang disediakan pemerintah per bulan untuk empat daerah

$D A_{i}=$ Nilai Penyimpangan diatas $b_{i}$

$D B_{i}=$ Nilai Penyimpangan dibawah $b_{i}$

$T_{i}=$ Jumlah RTS per tahun untuk setiap daerah

$S_{j} \quad=$ Total keseluruhan raskin yang didistribusi untuk 8 periode

$D A_{j}=$ Nilai Penyimpangan diatas $S_{j}$

$D B_{j}=$ Nilai Penyimpangan dibawah $S_{j}$

3. Fungsi Kendala Model

a. Kendala Pendistribusian Raskin

Persamaan :

$$
\sum_{i=1}^{m} a_{i} X_{i}+\left(D B_{i}-D A_{i}\right)=b_{i}
$$

Fungsi tujuan : $\operatorname{Min} \sum_{i=1}^{8}\left(D B_{i}+D A_{i}\right)$

b. Kendala pendistribusian raskin berdasarkan waktu pendistribusian

Persamaan :

$$
\sum_{i=1}^{m} \sum_{i=1}^{n} T_{i j} X_{i}+D B_{j}-D A_{j}=S_{j}
$$

Fungsi Tujuan : $\operatorname{Min} \sum_{i=8}^{9}\left(D B_{j}+D A_{j}\right)$

\subsubsection{Formulasi Masalah}

Perumusan masalah yang dibahas dengan model Goal Programming secara lengkap dapat disajikan sebagai berikut :

a. Mengoptimalkan pendistribusian raskin untuk daerah Manado

Tujuan :

$\operatorname{Min} \sum_{i=1}^{8}\left(D B_{i}+D A_{i}\right)+\sum_{i=8}^{9}\left(D B_{j}+D A_{j}\right)$

Syarat Ikatan

94704 XA1 + DB1 - DA1 $=757197$

$102687 X A 2+D B 2-D A 2=917580$

52396 XA3 + DB3 - DA3 $=523960$

59201 XA4 + DB4 - DA4 $=546477$
72741 XA5 + DB5 - DA5 $=953720$

$65880 \times A 6+D B 6-D A 6=1024575$

$59506 \times A 7+D B 7-D A 7=885410$

66172 XA8 + DB8 - DA8 $=916227$

1136448 XA1 +1232244 XA2 + $628752 X A 3+$ 769613 XA4 +872892 XA5 +790560 XA6 + $714072 \times \mathrm{XA} 7+661720 \times A 8+\mathrm{DB} 9-\mathrm{DA} 9=$ 80521691

b. Mengoptimalkan pendistribusian raskin untuk daerah Gorontalo

Tujuan :

$\operatorname{Min} \sum_{i=1}^{8}\left(D B_{i}+D A_{i}\right)+\sum_{i=8}^{9}\left(D B_{j}+D A_{j}\right)$

Syarat Ikatan

111860 XB1 + DB1 - DA1 = 932166

81066 XB2 + DB2 $-\mathrm{DA} 2=972800$

$61458 \times B 3+D B 3-D A 3=614583$

114294 XB4 + DB4 - DA4 = 879192

149808 XB5 + DB5 - DA5 $=1382850$

122016 XB6 + DB6 - DA6 $=1126301$

70517 XB7 + DB7 - DA7 = 1087137

105392 XB8 + DB8 - DA8 = 1053920

$1342320 \mathrm{XB} 1+810660 \mathrm{XB} 2+737496 \mathrm{XB} 3+$ 1485822 XB4 + 1498080 XB5 + 1586208 XB6 + $846204 \times B 7+1264704 \times B 8+D B 9-D A 9=$ 98030154

c. Mengoptimalkan pendistribusian raskin untuk daerah Tahuna

Tujuan :

$\operatorname{Min} \sum_{i=1}^{8}\left(D B_{i}+D A_{i}\right)+\sum_{i=8}^{9}\left(D B_{j}+D A_{j}\right)$

Syarat Ikatan

27642 XC1 + DB1 - DA1 $=271780$

$28339 \times C 2+D B 2-D A 2=340108$

20956 XC3 + DB3 - DA3 $=209563$

22386 XC4 + DB4 - DA4 = 268633

$27588 \times C 5+$ DB5 - DA5 $=402325$

$24986 \times C 6+D B 6-D A 6=432210$

$25097 \times C 7+D B 7-D A 7=355787$

25097 XC8 + DB8 - DA8 = 376455

331704 XC1 + 283390 XC2 + 251472 XC3 + 223860 XC4 + 331056 XC5 + 299832 XC6 + $326261 \times C 7+301164 \times C 8+$ DB9 - DA9 = 30120662

d. Mengoptimalkan pendistribusian raskin untuk daerah Tahuna

Tujuan :

$\operatorname{Min} \sum_{i=1}^{8}\left(D B_{i}+D A_{i}\right)+\sum_{i=8}^{9}\left(D B_{j}+D A_{j}\right)$

Syarat Ikatan 
24612 XD1 + DB1 - DA1 $=417606$
24957 XD2 + DB2 - DA2 $=358860$
26477 XD3 + DB3 - DA3 $=317724$
29424 XD4 + DB4 - DA4 $=294246$
26960 XD5 + DB5 - DA5 $=500252$
24417 XD6 + DB6 - DA6 $=496052$
31192 XD7 + DB7 - DA7 $=480876$
24526 XD8 + DB8 - DA8 $=367890$

246120 XD1 + 299484 XD2 + 244170 XD3 + 353088 XD4 + 323520 XD5 + 317421 XD6 + $374304 \times \mathrm{XD} 7+294312 \times \mathrm{XD} 8+\mathrm{DB} 9-\mathrm{DA} 9=$ 37827485

\subsubsection{Penyelesaian Model}

Tahapan berikutnya adalah mencari penyelesaian masalah dengan menggunakan perangkat lunak computer Lindo

\subsubsection{Analisa Hasil}

a. Berdasarkan analisis hasil Goal Programming di peroleh jumlah raskin yang didistribusi Berdasarkan Analisis hasil Goal Programming di peroleh jumlah raskin yang didistribusi untuk empat daerah pada periode 2004 -2011, dimana hasil analisis Goal Programming memberikan informasi jumlah raskin yang didistribusi untuk setiap daerah per bulan berdasarkan jumlah RTS, waktu pendistribusian dan total raskin yang disediakan pemerintah. Hasilnya dapat dilihat pada Tabel 6-9 dibawah ini.

Tabel 6 - Hasil Perhitungan dengan Lindo untuk raskin yang didistribusikan per bulan untuk Daerah Manado periode 2004-2011

\begin{tabular}{|l|l|}
\hline Tahun & Solusi Optimal (Kg) \\
\hline 2004 & 7.995407 \\
\hline 2005 & 8.935698 \\
\hline 2006 & 10.000000 \\
\hline 2007 & 13.786298 \\
\hline 2008 & 13.111176 \\
\hline 2009 & 15.552140 \\
\hline 2010 & 14.879340 \\
\hline 2011 & 13.846144 \\
\hline
\end{tabular}

Tabel 7 - Hasil Perhitungan dengan Lindo untuk raskin yang didistribusikan per bulan untuk Daerah Gorontalo periode 2004-2011

\begin{tabular}{|l|l|}
\hline Tahun & Solusi Optimal (Kg) \\
\hline 2004 & 8.333327 \\
\hline 2005 & 12.000098 \\
\hline 2006 & 10.000049 \\
\hline 2007 & 7.692372 \\
\hline 2008 & 9.230816 \\
\hline 2009 & 11.846167 \\
\hline 2010 & 15.416665 \\
\hline 2011 & 10.000000 \\
\hline
\end{tabular}

Tabel 8 - Hasil Perhitungan dengan Lindo untuk raskin yang didistribusikan per bulan untuk Daerah Tahuna periode 2004-2011

\begin{tabular}{|c|c|}
\hline Tahun & Solusi Optimal (Kg) \\
\hline 2004 & 9.832140 \\
\hline 2005 & 12.001411 \\
\hline 2006 & 10.000143 \\
\hline 2007 & 12.000045 \\
\hline 2008 & 14.583333 \\
\hline 2009 & 17.298086 \\
\hline 2010 & 11.418024 \\
\hline 2011 & 15.000000 \\
\hline
\end{tabular}

Tabel 9 - Hasil Perhitungan dengan Lindo untuk raskin yang didistribusikan per bulan untuk Daerah Bolaang Mongondow periode 2004-2011

\begin{tabular}{|c|c|}
\hline Tahun & Solusi Optimal (Kg) \\
\hline 2004 & 16.967577 \\
\hline 2005 & 14.379132 \\
\hline 2006 & 12.000000 \\
\hline 2007 & 10.000204 \\
\hline 2008 & 18.555342 \\
\hline 2009 & 21.094685 \\
\hline 2010 & 15.416645 \\
\hline 2011 & 15.000000 \\
\hline
\end{tabular}

b. Pendistribusian Raskin

Pada perencanaan pendistribusian raskin dapat dilihat bahwa pendistribusian raskin untuk berbagai daerah dengan menggunakan analisis Goal Programming dimana apabila nilai variabel negative (DA) dan nilai variabel positif (DB) bernilai nol maka dikatakan optimal sedangkan dalam penelitian ini masih ada yang kurang optimal karena pada kasus pendistribusian raskin masih ada nilai variabel negative (DA) dan nilai variabel positif (DB) yang tidak bernilai nol. Hal ini dapat dilihat dari pendistribusian raskin setiap bulan untuk masing-masing daerah. Hal tersebut dapat ditunjukan oleh nilai variabel negative (DB) dan nilai variabel positif (DA) pada fungsi kendala tujuan pendistribusian. Hal ini dapat dilihat untuk daerah Manado pada tahun 2007 yaitu kekurangan $3(\mathrm{Kg})$, daerah Gorontalo pada tahun 2009 yaitu kekurangan 1.3 (Kg), daerah Tahuna pada tahun 2010 kelebihan 69228.84 (Kg) dan daerah Bolaang Mongondow pada Tahun 2009 kekurangan $1.6(\mathrm{Kg})$.

\section{Kesimpulan}

Berdasarkan Analisis hasil Goal Programming di peroleh jumlah raskin yang didistribusi untuk empat daerah pada periode 2004-2011, dimana hasil analisis Goal Programming memberikan informasi jumlah raskin yang didistribusi untuk setiap daerah per bulan berdasarkan jumlah RTS, waktu pendistribusian dan total raskin yang disediakan pemerintah di masing-masing daerah adalah pada tahun 2004 untuk daerah Manado 7,9(kg) setiap KK, 
daerah Gorontalo 8,3(kg) setiap KK, daerah Tahuna 9,8(kg) setiap KK dan untuk daerah Bolaang Mongondow 16,9(kg) setiap KK. Pada tahun 2005 untuk daerah Manado 8,9 $(\mathrm{kg})$ setiap KK, daerah Gorontalo 12(kg) setiap KK, daerah Tahuna 12dan untuk daerah Bolaang Mongondow 14,3(kg) setiap KK. Pada tahun 2006 untuk daerah Manado 10(kg) setiap KK, daerah Gorontalo 10(kg) setiap KK, daerah Tahuna 10(kg) setiap KK dan untuk daerah Bolaang Mongondow $12(\mathrm{~kg})$ setiap KK. Pada tahun 2007 untuk daerah Manado 13,7(kg) setiap KK, daerah Gorontalo 7,6(kg) setiap KK, daerah Tahuna 12(kg) dan untuk daerah Bolaang Mongondow 10(kg) setiap KK. Pada tahun 2008 untuk daerah Manado 13,1(kg) setiap KK, daerah Gorontalo 9,2(kg) setiap KK, daerah Tahuna 14,5dan untuk daerah Bolaang Mongondow 18,5(kg) setiap KK. Pada tahun 2009 untuk daerah Manado $15,5(\mathrm{~kg})$ setiap KK, daerah Gorontalo 11,8 (kg) setiap KK, daerah Tahuna 17,2(kg) setiap KK dan untuk daerah Bolaang Mongondow 21(kg) setiap KK. Pada tahun 2010 untuk daerah Manado 14,8(kg) setiap KK, daerah Gorontalo 15,4(kg) setiap KK, daerah Tahuna 11,4(kg) setiap KK dan untuk daerah Bolaang
Mongondow 15,4(kg). Pada tahun 2011 untuk daerah Manado 13,8(kg) setiap KK, daerah Gorontalo 10(kg) setiap KK, daerah Tahuna 15(kg) setiap KK dan untuk daerah Bolaang Mongondow 15(kg) setiap $\mathrm{KK}$.

\section{Daftar Pustaka}

Anis, Nandiroh, dan Utami Agustin. 2007. Optimasi Perencanaan Produksi Dengan Metode Goal Programming.

Mauliyawati, Sundarso dan Kismartini. 2004. Studi Evaluasi Kinerja Program Raskin.Vol.1, No 1, Januari 2004, P: 158 - 174.

Produksi dengan Menggunakan Metode Goal Programming (studi kasus PT. Royal Standard). [Skripsi].

Siswanto. 2007. Operations Research. Jilid 1, Penerbit Erlangga, Jakarta. 